\title{
GOSSIP, SCANDAL, SHAME AND HONOR KILLING: A CASE FOR SOCIAL CONSTRUCTIONISM AND HEGEMONIC DisCOURSE
}

\author{
DR. AMANI M. AWWAD \\ State University of New York
}

\begin{abstract}
A critical assessment of the cultural factors involved in the phenomenon of honorkilling in the Middle East will be discussed in thispaper. Throughsocial constructionismand hegemonicdiscourse thefollowing issues will be addressed: First, the roleeach cultural factor (gossip, scandal, and shame) plays in legitimizing and perpetrating the violence of honorkilling. Second, unravel the mystery as to bow these cultural factors became an integral part of thesocial control apparatusaimed at controlling and dominating women. Third, understand theambivalent naturecharacterizing the role of agents of social control, including thestate, the criminal justicesystem and the community in dealing with honorkilling.
\end{abstract}

\section{What Is Honor Killing?}

Honor killing is a form of gender based violence perpetrated by a male family member, usually a brother or a father, against a female family member believed to have dishonored the family by engaging in immoral and unacceptable forms of sexual behavior (Baker, Gregware, \& Cassidy, 1999; Ruggi, 1998; Glazer \& Abu Ras, 1994; Kressel, 1981; Ginat, 1979). Family is the foundation of Middle Eastern society, which tends to be patriarchal, patrilineal and patrilocal in orientation (Ruggi, 1998). The status of the family is linked to its honor, which is the responsibility of female family members, especially daughters and wives (Ruggi, 1998). Women who are victims of rape 
and incest, usually perpetrated by a male family member, fall victim to this form of family aggression because it is believed that they have brought shame to the family. This leads us to raise the following question: How did these cultural factors evolve to be an integral part of the social control apparatus aimed at controlling, dominating and eventually killing women in the Middle East? It is imperative to address the historical roots of honor killing before addressing the cultural complexities of the social control apparatus of the phenomenon of honor killing.

According to Sharif Kanaana, a professor of Anthropology at Birzeit University, honor killing emerged in the pre-Islamic era (Ruggi, 1998, p.2). Professor Kanaana believes that honor killing reflects the patriarchal and patrilineal orientation of Middle Eastern society aimed at creating a system of social control designed to protect important familial power structures including reproductive powers. He contends that honor killing is not aimed at controlling women's sexual behavior; rather, it is aimed at protecting an important familial power structure, reproductive power (Ruggi, 1998). Shadia Sarraj of the Women's Empowerment Project at the Gaza Community Mental Health Project, further states that this code of honor is centered on the idea of a woman's virginity (Ruggi, 1998). A women's ard (ard in Arabic translates to honor in English) is a "commodity" that should be protected by the family and the community. Therefore, externally the women's behavior and dress code should be guarded and internally her hymen should be intact (Ruggi, 1998). To understand this complex code of honor one has to focus the analysis on the early Middle Eastern culture, specifically the pre-Islamic era.

\section{Historical Roots of Honor Killing}

Early pastoral societies of the Middle East were centered on the power and the privilege of the family that is linked to its chances and opportunity to access important contested societal resources. The communities were loosely organized and the absence of a centralized system of state control led to the creation of a cultural ideology maintained and enforced by the family and aimed at protecting its resources and improving its chances to access more resources. Therefore, the more resources the family owns, the higher the status it has among the community. Common cultural practices existed in early pastoral societies of the Middle East including giving complete power and authority to the adult males in the family to make important political and economic decisions. Further, in an effort to keep resources within the family, inheritances were passed down to the male lineage in the family and women were not allowed to inherit any property because they will pass it on to another family once they were married. However, as long as they remain single, women are considered an important commodity in the family. It is essential to keep single, and even married women, virginal and pure because of their reproductive function in the family. Women were endowed with the responsibility of bearing and raising healthy, strong male children for the family (Ruggi, 1998; Kressel, 1981; Schneider, 1971).

Honor killing continues to exist in the modern Middle East despite the influences of colonialization and industrialization. This cultural practice is not associated with Islam in form. To link honor killing to Islam, or any religion of the Middle East, will only manage to undermine the ideological complexities of gender dynamics in the Middle East which are characterized by patriarchy and patrilineal orientation. Ginat (1979) perceived honor killing to be linked to Islam, specifically to the Koran. However, other experts perceive the phenomenon of honor killing to be a complex social phenomenon closely related to the patriarchal system aimed at controlling and dominating women of the Middle East (Baker, Gregware, \& Cassidy, 1999). In general, experts on honor killing tend to agree with the fact that family honor is linked to the sex organs of daughters and wives (Baker, Gregware, \& Cassidy, 1999; Kressel, 1981; Ginat, 1979; Schneider, 1971). 


\section{Cultural Factors: Hegemonic Discourse}

To understand the complexity of the cultural factors involved in the phenomenon of honor killing we must focus on the hegemonic nature of these factors. This will help us understand how these cultural factors play an important role in the social control apparatus created to control, dominate and subordinate women of the Middle East. Nader (1989) uses Gramsci's definition of hegemony to explain how these cultural factors became part of the cultural hierarchy of the social control apparatus that lends legitimacy to the current system of social control. According to Gramsci (1971), hegemony is believed to be a system of thoughts developed over time that tends to reflect the interest of certain classes and groups in society, therefore, making them universal ideas. These ideas or "dogmas" are produced and reproduced through the work of a specific group in society, "The Intellectual Elites." Through societal consent these "dogmas" became part of the social control apparatus. Gramsci's form of hegemony is created and maintained though consent rather than using coercion, force or any form of state domination. In other words, society has accepted these "dogmas" due to the brilliant work of "The Intellectual Elites." Gramsci's model of hegemony reflects power dynamics or "dogmas" passed from top to bottom from "The Intellectual Elites" to the uneducated masses. Foucault, however, has a different idea or conception of hegemony (Ritzer, 2000, 1996; Wallace \& Wolf, 1999).

Foucault and Gramsci (Ritzer, 200, 1996 and Foucault, 1982), are interested in understanding the process by which "dogmas" are universalized and accepted by the members of a given society. However, Foucault focuses on the ideas of power and truth that he considers to be important elements of hegemony. In essence, hegemonic discourse is accomplished when values and beliefs are universalized, created and recreated. What is interesting about hegemonic dynamics is that certain conceptions of reality and cultural practices become dominate, therefore restricting any alternative conceptions of reality as long as they do not fit the agenda or the interest of a specific class or segment of a society. This process reflects the struggle between truth and power. The end result of the hegemonic discourse dynamics is that certain conceptions of reality become the foundation of the cultural practices of the society as whole. Therefore, making these cultural practices the norm and any deviation is considered unacceptable behavior (Ritzer, 2000, 1996; Glazer \& Abu Ras, 1994; Nader, 1989; and Foucault, 1982). Foucault and Gramsci's ideas of hegemonic discourse can help us understand gender dynamics and cultural practices that facilitated and lend legitimacy to the current code of honor practiced in the Middle East.

\section{Femininity and Masculinity: Hegemonic Discourse}

Gender dynamics in the Middle East reflect the powerful grip sexism as an ideology has on the society as whole. Feminist scholars from the west and the non-western world, have theorized as to how this ideology was created, maintained, by whom and why? Therefore, the ambiguity surrounding this process is clarified and essentially seen as a power struggle. Hegemony and ideology furthered the creation of a reality and truth that is aimed at benefiting a certain segment of society so as to control its interest and at the same time manage to keep the rest of society subordinate (Baker, Gregware, \& Cassidy, 1999; Johnson, 1997; Chafetz, 1990; Millet, 1970, Ortner, 1978, Schneider, 1971). The question to address is how the realities of masculinity and femininity allowed for the creation of a system of social control composed of cultural practices including shame, scandal, gossip and, most importantly, family honor and honor killing.

According to Kandiyoti (1988), masculinity and femininity as understood and practiced in the Middle East created two sets of realities, one characterized by dominance and control while the other characterized by submissiveness and sexual purity. Masculinity constitutes an achieved status; men have to work constantly to protect and achieve a higher status of masculinity. On the other hand, femininity is an ascribed status with predetermined traits, obligations and set of rules that women have no choice but to accept the reality 
that is being imposed on them by the culture, specifically by the male patriarchal and patrilineal culture of the Middle East.

Femininity entails negative cultural traits for women in the Middle East. It involves a set of rules, duties and obligation that limit women's chances and access to important societal resources, therefore rendering them powerless and weak in the face of cultural struggles. An integral part of this constructed reality is that in which women's sexual identities are defined and regulated by the patriarchal culture of the Middle Eastern society. Virginity and sexual purity is expected of women in the Middle East of all ages and social status, married and single. A powerful system of social control was created to protect the sexual purity of women in the Middle East. This system involves factors such as shame, scandal and gossip aimed at protecting the prestigious status of the patrilineal family. This system of social control puts the burden on women in protecting their own sexual purity. If shame is brought to the family then, women are to blame; this shame occurs even if their male counterparts raped them, lending to the ideology of blaming the victim. (Baker, Gregware, \& Cassidy, 1999; "The Price of Honor," 1999, January 18).

\section{Honor Killing and Family Honor: A Sociological Analysis}

Family honor and codes of honor, serve as important functions in protecting the social status and standing of the family in their community. Family honor is used to protect the economic interest of the family within the competitive society of the Middle East. "Thus honor can be thought of as the ideology of a property holding group which struggles to define, enlarge, and protect its patrimony in a competitive arena" (P. Schneider, 1969 In J. Schneider, 1971, page 2). What Schneider is referring to is the code of honor used by one group, males, to protect its interest and advance its property holding since property is what defines the social status of the family in the Middle East.
Then why is it that such responsibility falls on the shoulders of women of the Middle East? This is a valid question to raise, and the answer lies in the fact that it is of great interest for the Middle Eastern family to be large and, at the same time, protect its lineage. Therefore, the female's reproductive function can fulfill this obligation by women maintaining their sexual purity. The code of honor as boundary maintenance for the family allows it to define, protect and maintain its boundary in the confusing and loosely organized culture of the Middle East. The code of honor encourages feelings of unity and loyalty to the groups.

\section{The Functions of Gossip}

Gossip is at the center of a family's code of honor. Once shame threatens the family's honor, it becomes a concern of the entire community and not just the family. Therefore, the family is pressured through the continuation of gossip to take the necessary steps to purify or "purge" its honor. This results in restoring the family's social standing in the neighborhood and the community. From a structural functionalist perspective, gossip serves to unify the community and establish stability and order that are essential to the survival of the family and society. Gossip, scandal and shame from the Durkhemian sense functions to clarify cultural and normative boundaries for the society as a whole. Gossip is a tool used by community members to spread the unpleasant reality or truth that a certain family's honor has been tarnished, and therefore a family's social and prestigious status is in danger. This is sometimes referred to as "losing face". Gossip then becomes a tool used to remind the family of its shame (Gluckman, 1963; Campbell, 1964; Kressel, 1981; Gilmore, 1987; Accad, 1991; Lansky, 1995; Turner, 1995). Ginat (1979) further states that violence against women will only occur if her illicit sexual activities become public knowledge. Once the illicit sexual activities become public knowledge, the community will exert tremendous pressure on the family to correct the situation, which is sometimes referred to as "saving face." Therefore, public accusation 
leads to violence against the woman who stained the family honor by bringing shame to it.

Next, the focus shifts to discussing the ideological roots of cultural practice of honor killing and the ideology of sexism that allowed for the patriarchal, patrilineal and patrilocal family to flourish and become the dominant economic and social institution in the Middle East. The ideology of sexism is to be blamed directly for the ambivalent approach the state and its supporting social control apparatus, including the criminal justice system, have taken in regard to honor killing. Some experts perceive this ambivalent attitude as an ideologically motivated and carefully constructed move to not challenge the existing status quo supported by old traditional beliefs and cultural practices that have existed for decades (Baker, Gregware, \& Cassidy, 1999; Alonso, 1995; Derne, 1994; Glazer \& Abu Ras, 1994). Sexism as an ideology has influenced, facilitated, and even lended legitimacy to existing penal codes regarding honor killing which continue to be practiced in the Middle East with little or no challenge at by the citizens of the Middle East, with the exception of the few challenges raised by feminist activists struggling to protect women's lives (Ruggi, 1998). Let us examine the ideological implications of a selected sample of these penal codes.

\section{Honor Killing and the Law}

The following excerpt of penal codes is taken from the Equality Now Organization's report in July, 1999, entitled "Why equality now?" Article 548 from the Syrian penal code states:

1. He who catches his wife or one of his ascendants, descendants or sister committing adultery (flagrante delicto) or illegitimate sexual acts with another and he killed or injured one or both of them benefits from an exemption of penalty ("Why Equality Now?" 1999, July, p. 8).
The above penal code is a flagrant disregard for human life and what is interesting is that the state is allowing this code to exist on the book; therefore, it can be considered a form of state crime in defense of family honor. The state has the power to eradicate injustice but rather decides to lend legitimacy and legal support for a violent and unjust cultural practice. What is communicated in the above penal code is that having honor is more important than a human life, and hence it is a necessary evil to sacrifice human lives, usually innocent women, for the sake of protecting family honor. In the end, a family's status is restored, though not completely. Another issue raised by this penal code is what is referred to as superior/inferior sets of values and beliefs which work to further enhance the sexist ideology of the patriarchal, patrilineal and patrilocal orientation of the Middle Eastern family and specifically, and society in general.

Another example of penal code is taken from Jordan, penal code no. 16, 1960 which states the following:

Article 340. He who discovers his wife or one of his female unlawful, committing adultery with another, and he kills, wounds, or injures one or both of them, is exempt from any penalty. He who catches his wife, or one of his female ascendants or descendants or sisters with another in an unlawful bed and he kills or wounds or injures one or both of them, benefits from a reduction of penalty" ("Why Equality Now?" 1999, July, pp. 7-8).

First, one should notice the similarity both codes (Article 548 from the Syrian penal code and Article 340 from the Jordan penal code) share in terms of legal terminology and the type of punishment rendered, if any, when dealing with honor killing. The message communicated in the previous penal codes is that family honor must be protected at any cost, even if innocent lives are sacrificed in the process. A subtle and deadly hidden agenda is communicated through the above penal codes, and possibly stressed in the countless penal codes not discussed here, that honor killing has a Durkhemian function of restoring the family's morality since it was shattered by 
shame and scandal. It is a "plea" to restore morality and at the same time conform to the moral principles of sexual purity and virginity (Kressel, 1981).

In an updated report by the Equality Now Organization, titled "Why Equity Now?," published in November of 1999, several illustrative examples were given, reflecting the state's refusal to reform its existing penal codes regarding honor killing. A case in point is Jordan, where the parliament defeated an amendment to abolish Article 340 of the penal code that provides a reduced sentence for men who murder their female relatives in cases of honor killing. The penal code was perceived to be a discriminatory law that needed to be repealed and removed permanently from the systems of penal codes. In September 1999, a draft law amending this provision was submitted to the parliament with the proper petition and signatures required by Jordan law, collected by group of activists from all walks of life-journalists, lawyers and educators. A storm of challenges and opposition erupted in the Jordanian Parliament, and the challenges were centered on the following theme:

Several members of parliament, however, organized opposition to the amendment. Mahmoud Kharabsheh, a member of the House Legal Affairs Committee, was quoted as saying the amendment was "an invitation to obscenity," and that females are the ones who take the initiative and demonstrate consent to committing adultery" ("Why Equality Now?" 1999, November, p. 2).

Mr. Kharabsheh was able to collect signatures from 27 parliament members who shared his views and on November 21, 1999, the amendment was defeated with only one parliament member who spoke on behalf of it. Meanwhile, women in Jordan continue to fall victim to honor killing. According to the Equality Now Organization, it has been reported in the Jordan Times that 22 women died in 1998 and more than 14 cases have been reported in 1999 ("Why Equality Now?" 1999, November, p. 2). The irony is that Mr. Kharabsheh, much like his supporters, lashed out against women once his authority and masculinity were challenged, as he perceived this amendment would most likely do. This is a typical response taken by men who feel that shame threatens their masculinity that they constantly had to work on to achieve (Baker, Gregware, \& Cassidy, 1999; Johnson, 1997; Turner, 1995; Kandiyoti, 1988). This archaic notion of family honor, with its structural functionalist orientation, Durkhemian sense of morality, and the "plea for renewed adherence to norms" pointed out by Kressel (1981), have to be challenged because such arguments can no longer provide legitimacy to the continuation of this archaic code of family honor and shame. Perhaps the social conflict theory of gender dynamics will offer a sound argument that will address the unjust and discriminatory nature of the code of honor and any existing laws used to dominate, exploit and control women in the Middle East.

\section{Recommendations}

The stand I take in regard to honor killing is influenced by the great works of feminist scholars such as Andrea Dworkin, Catherine McKinnon and Mary Daly, to name a few. In my opinion, social conflict analysis provides arguments that would allow us to perceive this code of honor and various unjust cultural practices in a different light. From a social conflict perspective, gossip is a tool of exploitation used by the powerful elites in order to enforce conformity to the existing cultural norms surrounding female sexuality. The dangerous reality surrounding gossip, scandal, shame and honor killing need to be exposed and challenged by the society as a whole, not just by the feminist activists, who are struggling alone against the powerful cultural ideologies of the system of social control. The Middle Eastern society needs to follow the Western world model that involves the following steps used in dealing with domestic violence: First, breaking the walls of silence, or better said, eliminating the conspiracy of silence. Second, treating these forms of family aggression as horrific crimes punishable by stiffer sentences. And finally, changing the existing laws (penal codes) so as to provide protection for women against family aggression. This is 
a long road to travel and activists cannot do it alone. The state, the powerful elite and its supporting social control apparatus need to join in the struggle to change existing dangerous cultural attitudes and practices of honor killing because women's lives are valuable and deserve to be protected (Baker, Gregware \& Cassidy, 1999; "The Price of Honor," 1999, January 18; Glazer \& Abu Ras, 1994). The author argues that the Middle Eastern culture could learn from the Western Model. What is desperately needed in the Middle East is a public campaign to bring attention to the horrific crimes of honor killing while forcing the Middle Eastern culture to question the legitimacy of such crimes against women. According to social conflict experts, honor killing is used to further the interests of the patriarchal, patrilineal and patrilocal society of the Middle East. Social conflict analysis constructs a different reality of gender dynamics that emphasizes the continuation of the struggle for power at all levels-political, economic, social and even personal.

This struggle for power is reflected in the way society constructs the appropriate gender roles for men and women. Femininity and masculinity as constructed and integrated into society give men complete power and control and, at the same time, take power away from women and impose a reality on women which they had no part in constructing or are even allowed to challenge, rendering them powerless. Family aggression, including honor killing and domestic violence, best illustrates this oppressive reality women fall victim to and continue to struggle to change despite the obstacles they face being powerless.

The ideological struggle for power facilitated the propaganda behind the conspiracy of silence used to cover and keep secret all forms of family aggression, including domestic violence, honor killing and marital rape. This conspiracy of silence is reflected by the fact that there are no unified crime reports and data on honor killing that is desperately needed by feminist activists. This conspiracy of silence has even impacted me. I was hesitant to take on this research project for fear of reprisal from my family. I decided I could no longer participate in this conspiracy of silence; honor killing needs to be exposed, challenged and eventually eradicated from the fabric of Middle Eastern culture. It is my duty and obligation to my sisters in the Middle East.

\section{Acknowledgements}

The author would like to acknowledge the editorial suggestions provided by the anonymous reviewer and Ann Marie Hickey, the editor of Social Thought and Research. I am deeply indebted to their attention and insightful suggestions. I would also like to thank Patricia Ann-Mary (Pat Ann) Frenette for helping me with editing and editorial changes of this manuscript from its beginning to its final form. Without Pat Ann's support this project could not have been completed.

\section{References}

Accad, E. (1991). Sexuality and sexual politics: Conflicts and contradictions for contemporary women in the Middle East. In C.T. Mohanty, A. Russo, \& L. Torress (Eds.), Third world women and the politics offeminism (pp. 237-250). Bloomington, IN: Indiana University Press.

Alonso, A. (1995). Rationalizing patriarchy: Gender, domestic violence and law in Mexico. Identities: Global Studies in Culture and Power, 2(1-2), 29-47.

Baker, N. V., Gregware, P. R. \& Cassidy, M. A. (1999). Family killing fields: Honor rationales in the murder of women. Violence Against Women, $5(2), 164-184$

Campbell,J. K. (1964). Honor, family and patronage: A study of institutions and moral values in a Greek mountain community. Oxford: Clamendon Press.

Chafetz,J.S. (1990). Gender equity: An integrated theory of stability and change. Sage Library of Social Research 176, Sage Publication.

Derne, S. (1994). Hindu men talk about controlling women: Cultural ideas as tool of the powerful. Sociological Perspectives, 37(2), 203-227.

Foucault, M. (1982, Summer). The study of power. Critical Inquiry, 8,777795.

Gilmore, D. D. (1987). Aggression and community: Paradoxes of Andalusian culture. Yale University Press.

Ginat, J. (1979). Illicit sexual relationships and family honor in Arab society. Israeli Studies in Criminology, 10, 179-202. 
Glazer, I. M. \& Abu Ras, W. (1994). On aggression, human rights, and hegemonic discourse: The case of a murder for family honor in Israel. Sex Roles, 30(3-4), p. 269.

Gluckman, M. (1963, June). Gossip and scandal. Current Anthropology, 4(3), 307-316.

Gramsci, A. (1971). In Q. Hoane \& G. N. Smith (Eds. and Trans.), Selections from the prison notebooks of Antonio Gramsci. International Publisher.

Johnson, A. G. (1997). Thegender knot:Unrazelingourpatriarchal legacy. Temple University Press.

Kandiyoti, D. (1988, September). Bargaining with patriarchy. Gender and Society, 2(3), 274-290.

Kressel, G. M. (1981, April). Sororicide/Filiacide: Homicide for family honor. Current Antbropology, 22(2), 141-158.

Lansky, M. R. (1995, August). Shame and the scope of psychoanalytic understanding. American Behavioral Scientist, 38(8), 1076-1090.

Millet, K. (1970). Sexual Politics. New York: Avon.

Nader, L. (1989). Orientalism, occidentalism and the control of women. Cultural Dynamics, 2, 323-355.

Ortner, S. B. (1978). The virgin and the state. Feminist Studies, 4, 19-35.

"The Price of Honor." (1999, January 18,). Time(153), p. 55.

Ritzer, G. (1996). Modern sociological theory ( $4^{\text {th }}$ ed.). New York: McGrawHill.

Ritzer, G. (2000). Modern sociological theory (5th ed.). McGraw-Hill Higher Education.

Ruggi, S. (1998, Spring). Honor killing in Palestine: Commodifying honor in female sexuality. Middle East Report.

Schneider, J. L. (1971). Of vigilance and virgins: Honor, shame and access to resources. Mediterranean Etbnology, 10, 1-24.

Turner, F. (1995, August). Shame, beauty, and the tragic view of history. American Behavioral Scientist, 38(8), 1060-1075.

Wallace, R. A. \& Wolf, A. (1999). Contemporary sociological theory: Expanding the classical tradition $\left(5^{\text {th }}\right.$ ed.). Prentice Hall.

"Why equality now?" (1999, July). Equality Now Organization.

"Why equality now?" (1999, November). Equality Now Organization.

\section{GODLy MASCULINTITIES: GENDER} Discourse among the Promise Keepers

JOHN P. BARTKOWSKI

Mississippi StateUniversity

Social Thought \& Research, 2002, Vol. 24, 1\&2

Abstract

At the peak of its prominence, the Promise Keepers had attracted criticism from many quarters. Wore recently, thisecungelical men's movement has struggled to retain the cisibility it once enjoyed. Using insights from cultural theory, I analyze a select sample of best-selling men's manuals representing warious advice genres within this movement. Iargue that PK gender discourses bave given rise to four eviangelical archetypes of godly manhood: the Rational Patriarch(traditional masculinity), the Expressize Egalitarian (men's liberationism), the Tender Warrior (poeticized manhood), and the Multicultural Man (interracial masculinity). Iexplore bow PKluminaries utilize two rhetorical devices-discursive tacking and gendered metaphors-to manage the tensions and contradictions that sur. facewithin and among thesediscourses. These archetypesenable the Promise Keepers to define themselves with reference to othernewsocial movements. Multiple depictions of godly manhood contributed to the rapid rise of this evangelical men's movement during the 1990s, and may beone sorrce of its recentdedine.
"I express my thanks to the anonymous reviewers at Journal of Social Thought and Researcb for their insightful remarks on a previous version of this manuscript. All interpretations presented here are my own. 